\title{
The added value of biomarker analysis to the genesis of plaggic Anthrosols; the identification of stable fillings used for the production of plaggic manure
}

\author{
Jan M. van Mourik, Thomas V. Wagner, J. Geert de Boer, and Boris Jansen \\ Institute for Biodiversity and Ecosystem Dynamics, University of Amsterdam, Science Park 904, \\ 1098 XH Amsterdam, the Netherlands \\ Correspondence to: Jan M. van Mourik (j.m.vanmourik@uva.nl)
}

Received: 13 November 2015 - Published in SOIL Discuss.: 15 January 2016

Revised: 17 May 2016 - Accepted: 26 May 2016 - Published: 4 July 2016

\begin{abstract}
Plaggic Anthrosols are the result of historical forms of land management in cultural landscapes on chemically poor sandy substrates. Application of plaggic manure was responsible for the development of the plaggic horizons of these agricultural soils. Pollen diagrams reflect aspects of the environmental development but the interpretation of the pollen spectra is complicated due to the mix of the aeolian pollen influx of crop species and species in the surroundings, and of pollen occurring in the used stable fillings. Pollen diagrams and radiocarbon dates of plaggic Anthrosols suggested a development period of more than a millennium. Calluna is present in almost all the pollen spectra, indicating the presence of heath in the landscape during the whole period of soil development. Optically stimulated luminescence dating of the plaggic horizon made clear that the deposition of plaggic covers started in the 16th century and accelerated in the 18th century. The stable fillings, used for the production of plaggic manure and responsible for the rise of the soil surface, cannot be identified with pollen diagrams alone. Biomarker analyses provide more evidence about the sources of stable fillings. The oldest biomarker spectra of the plaggic horizons of three typical plaggic Anthrosols examined in this study were dominated by biomarkers of forest species such as Quercus and Betula while the spectra of middle part of the plaggic horizons were dominated by biomarkers of stem tissue of crop species such as Secale and Avena. Only the youngest spectra of the plaggic horizons were dominated by biomarkers of Calluna. This indicates that the use of heath sods as stable filling was most likely introduced very late in the development of the Anthrosols. Before the 19th century the mineral component in plaggic manure cannot be explained by the use of heath sods. We conclude that other sources of materials, containing mineral grains must have been responsible for the raise of the plaggic horizon.
\end{abstract}

Plaggic Anthrosols occur in cultural landscapes, developed on cover sands. These chemical poor Late-glacial aeolian sand deposits dominate the surface geology of an extensive area in northwestern Europe. Plaggic Anthrosols are the characteristic soils that developed on ancient arable fields, fertilized with plaggic stable manure. Plaggic Anthrosols have a complex genesis and are valuable records of environmental and agricultural history (van Mourik et al., 2011).
In previous paleopedological studies of such soil records in The Netherlands (van Mourik et al., 2011, 2012a, b), information was unlocked by application of pollen analysis, radiocarbon $\left({ }^{14} \mathrm{C}\right)$ and optically stimulated luminescence (OSL) dating. Radiocarbon dates of soil organic carbon, extracted from humic horizons from plaggic Anthrosols, suggested the start of sedentary agriculture between 3000 and 2000 BP but are not indicative for the age of the plaggic sediments due to the complexity of soil organic carbon in plaggic sediments (Mook and Streurman, 1983; van Mourik et al., 1995). It was assumed that farmers used organic sods as stable fill- 
ing, firstly dug on forest soils and later on heaths for the production of stable manure to fertilize the fields. The mineral fraction of the sods was supposed to be responsible for the development of the plaggic horizon and the raise of the land surface. OSL dating applied on quartz grains extracted from plaggic sediments provides more reliable ages of the plaggic sediments. The OSL dates suggested that the rise of the plaggic horizons started in the 16th century and accelerated in the 18th century (Bokhorst et al., 2005). This is rather well in line with historical data, as presented by Spek (2004, p. 965).

The use of ectorganic matter from forest soils in the Dutch cover sand area must have been strongly reduced in the 11-13th century, due to commercial forest clear cuttings as recorded in archived documents (Vera, 2011). This deforestation resulted in a regional extension of sand drifting and the managers of the heaths had to protect their valuable ecotopes against this "historical environmental catastrophe" (Vera, 2011).

Heaths were already present in the Late Paleolithic landscape (Doorenbosch, 2013) and played a ceremonial role in the society of our ancestors. People already had the knowledge to manage the heath as sustainable grazing areas for cattle (Doorenbosch, 2013).

The use of heath for sheep grazing and other purposes as honey and oil production could continue until the middle of the 18th century (Vera, 2011). In the southeastern Netherlands sustainable use of the heaths was promoted by many management rules and laws (van Mourik, 1987; Vera, 2011). Over the course of the 18th century, the population growth resulted in an increasing food demand. In the course of the 18th century, the deep stable economy was introduced and the booming demand for manure resulted in intensification of manure production. Farmers started with the use of heath sods as (additional) stable filling (Spek, 2004). This caused heath degradation and initiated the second extension of sand drifting. The use of sods finished at the end of the 19th century after the introduction of chemical fertilizers (Spek, 2004).

Through the combination of OSL and ${ }^{14} \mathrm{C}$ dating, historical records and the conventional paleoecological proxy of fossil pollen analysis we have a good impression of the paleoecological environment and the age of such deposits. However, it remains problematic to reconstruct the combination of crop residues and various materials used by farmers as stable filling to produce the stable manure, together responsible for the rise of the surface of Anthrosols. This is also hindering a detailed interpretation of the agricultural practices and shifts therein related to the plaggic agriculture system, and specifically the timing of the onset of the intensive heath sod driven deep stable agriculture with which plaggic Anthrosols are most commonly associated. To address this issue, in the present study we expanded our paleoecological toolset with an adapted application of the recently developed biomarker approach (Jansen et al., 2010). This biomarker approach consists of a combination of analytical chemical analysis and modeling with the VERHIB model to unravel concentration patterns of higher chain length $\left(\mathrm{C}_{20}-\mathrm{C}_{36}\right)$ n-alkanes of higher plant origin preserved in a soil or sedimentary archive into the groups of species responsible for their production (Jansen et al., 2010). The approach was originally developed to unravel past local vegetation composition. Upon successful application in a tropical ecosystem setting (Jansen et al., 2013), its applicability in paleopedology was explored (van Mourik and Jansen, 2013). This pilot application concerned a polycyclic soil sequence in driftsand deposits. It showed that the comparison of pollen and biomarker spectra allowed us to indicate the plant species responsible for carbon sequestration in the humic horizons (van Mourik and Jansen, 2013). An important conclusion was that biomarker analysis showed promise not only in the reconstruction of past local vegetation composition of a specific site, but also in studies where the emphasis lies not on the vegetation per se, but rather on reconstructing various sources of soil organic matter input (van Mourik and Jansen, 2013).

The goal of the present study was to further explore the applicability of biomarker analysis as part of a multi-proxy reconstruction aimed at unraveling the sources of stable fillings used for the production of plaggic manure in the context of the historic development of the plaggic agriculture ecosystem. For this, we applied biomarker analysis on three previous investigated plaggic Anthrosol.

\section{Materials and methods}

\subsection{Profile selection}

The distribution area of plaggic Anthrosols in northwestern Europe is indicated in Fig. 1. Pape (1972) published the first map of the distribution of plaggic agriculture in northwestern Europe. Bastiaens and van Mourik (1995) found traces of intensification and extension of this area in Vlaanderen (Belgium) while van Mourik (1999b) also reported plaggic Anthrosols in Schleswig (Germany). Beside this area with "real" plaggic Anthrosols, Spek (2004, p. 724) summarized information about the occurrence of soils with some evidence of application of plaggic manure in the Atlantic coastal zones of Norway, Denmark, France, Galicia, Scotland and Ireland (soil classification according to ISRIC-FAO, 2006).

For this pilot study we selected three previously investigated plaggic Anthrosols in the Netherlands with an undisturbed plaggic horizon: Valenakker, Nabbegat and Posteles (Fig. 2). Pollen diagrams, ${ }^{14} \mathrm{C}$ and OSL dates of these profiles were available and previously published separately in various articles. Here we combined these, and re-sampled the plaggic horizons of the profiles for biomarker analysis and new fossil pollen analysis to allow for comparison. Vertical sampling resolution was the following: Valenakker $20 \mathrm{~cm}$, Nabbegat and Posteles $10 \mathrm{~cm}$.

Valenakker (van Mourik et al., 2012b) is situated southwest of the city Weert (middle Limburg) on the sport fields of 


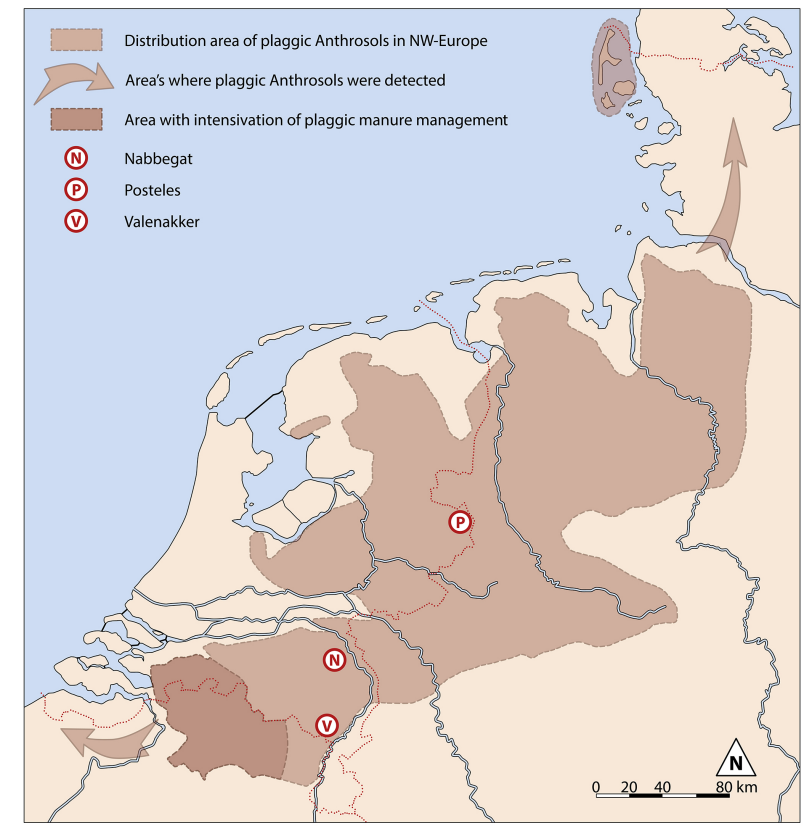

Figure 1. The location of sampled profiles Valenakker, Nabbegat and Posteles in the distribution area of plaggic agriculture.

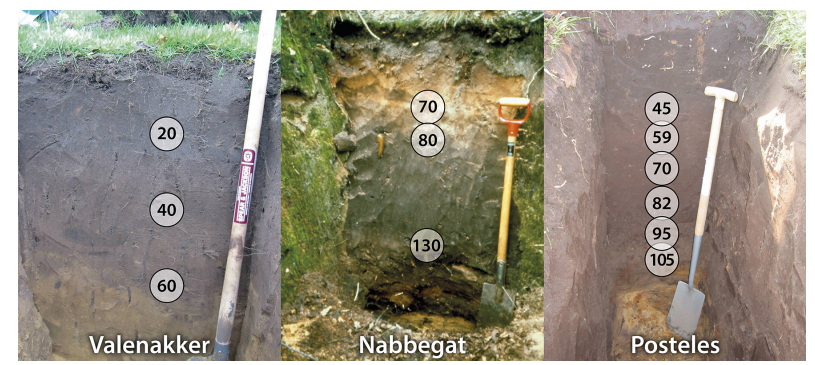

Figure 2. The plaggic Anthrosols Valenakker, Nabbegat and Posteles. The location of the OSL samples are indicated in the white circles (depth in $\mathrm{cm}$ ); the locations of the profiles are indicated in Fig. 1.

a former college. As a result, during the 20th century the soil has never been ploughed or subjected to land consolidation. This profile has never been affected by roots of Zea mays, introduced in The Netherlands in the middle of the 20th century (van Mourik and Horsten, 1995).

Nabbegat (van Mourik et al., 2012a) is situated on the Maashorst (eastern North-Brabant). The plaggic deposits were buried by drift sand around AD 1800. Consequently, the plaggic deposits have perfectly been protected against damage by land consolidation or pollution afterwards (van Mourik et al., 2012a). The site is now vegetated by oak and birch trees. Roots of these trees may have caused input of organic matter by decomposed roots in the upper part of the plaggic horizon (Fig. 3).

Posteles (van Mourik et al., 2011) is situated in Twente (eastern Overijssel). The landowner informed us that dur-

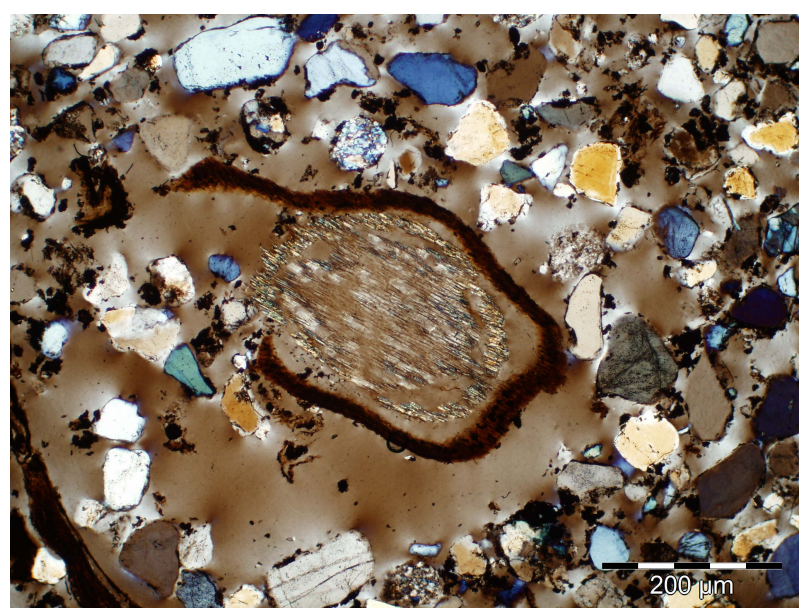

Figure 3. Cross-section of a (living) tree root in the thin section of the 2 Aan of Nabbegat $(70-80 \mathrm{~cm})$. Characteristic is the double fringing of the root tissue. Such roots were only found in the upper part of the 2Aan of Nabbegat. Roots of crop species were not found in the thin sections of the three profiles; they decompose rather fast compared with tree roots.

ing the last three generations this land was never subjected to deep ploughing or land consolidation but since $1960 \mathrm{Zea}$ mays was regularly sowed. In contrast to Valenakker and Nabbegat we can expect biomarkers of this deep rooting cultivated plant.

\subsection{Pollen analysis}

Pollen diagrams of plaggic Anthrosols provide paleoecological information about plant species, present on site and in the region during the formation of the plaggic horizon. Previous research showed that pollen grains, infiltrated in soils and incorporated in plaggic deposits, are well preserved in the anaerobic and acid microenvironment of excremental aggregates (van Mourik, 1999a, 2001) (Figs. 4, 5).

Samples for pollen extraction were collected in $10 \mathrm{~mL}$ tubes in profile pits. For a correct matching of pollen and biomarker spectra of the plaggic deposits, the same samples were treated for both pollen and biomarker extraction and analysis. The pollen extractions were carried out using the tufa extraction method (Moore et al., 1991, p. 50). For the identification of pollen grains, the pollen key of Moore et al. (1991, p. 83-166) was applied. Pollen scores were based on the total pollen sum of arboreal and non-arboreal plant species. For the estimation of the pollen concentrations of the various soil horizons, the exotic marker grain method was applied (Moore et al., 1991, p. 53).

\section{$2.3{ }^{14} \mathrm{C}$ and OSL dating}

The determination of the age of plaggic deposits is subjected to various complications (Spek, 2004). Pollen strati- 


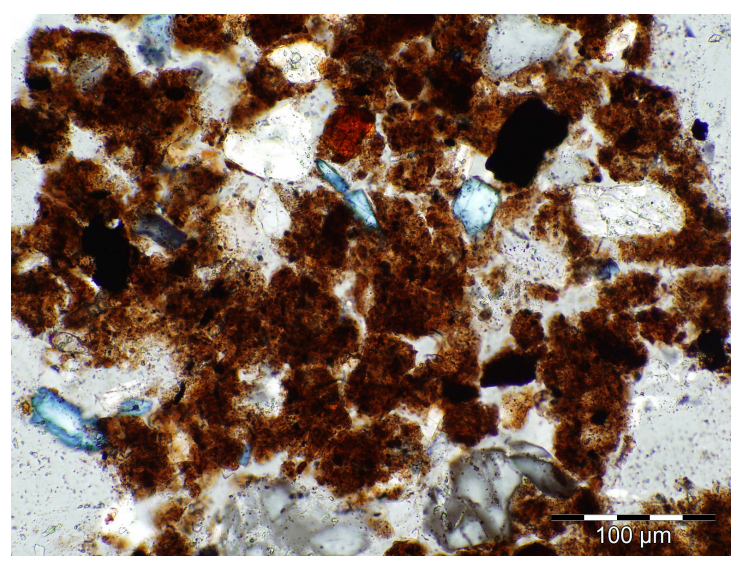

Figure 4. Distribution pattern of organic aggregates in a thin section of the Aan of Valenakker $(40-50 \mathrm{~cm})$. In the fabric of the aggregates are charcoal particles visible.

fication is disturbed by bioturbation and ploughing. Besides, the pollen content is a mix of the regular pollen influx and pollen in stable fillings, used for the production of stable manure (van Mourik et al., 2011). The ages of humic horizons of buried Podzols cannot be correctly determined by ${ }^{14} \mathrm{C}$ dating due to the complex composition of soil organic carbon (van Mourik et al., 1995). During a period of active soil formation, hard decomposable organic carbon can accumulate in the Ah horizon, especially in the humin fraction but also in the humic acid fraction. The accumulation of charcoal fragments in the organic aggregates is especially responsible for the overestimation of the ${ }^{14} \mathrm{C}$ ages (Fig. 4). During the Early Holocene small amounts of charcoal fragments were released after (natural) forest fires, but the amount increased drastically in the iron time due to the charcoal production for the melting of iron from placic horizons and iron stone (Beukenkamp and Sevink, 2005). The age of the humic acid fraction was considered the best estimate of the moment of fossilization of the Ah horizon after burying by driftsand. The difference between humin and humic acids ages was interpreted as a measure for the period of soil activity and humin accumulation. Later, OSL dating confirmed that radiocarbon dates, not only of the humin fraction but also of the humic acids, overestimate the true ages (Bokhorst et al., 2005).

Conventional radiocarbon dating of humin and humic acids showed in presented diagrams, extracted from plaggic deposits, was performed in the CIO (Centre for Isotope Research of the University of Groningen).

OSL dates provide reliable information about the moment of fossilization of plaggic material under the rising furrow because the quartz grain were perfectly bleached during active ploughing (Bokhorst et al., 2005). OSL dating of quartz grains, extracted from plaggic deposits, was performed in the NCL (Netherland Centre for Luminesce Dating, Wageningen University).

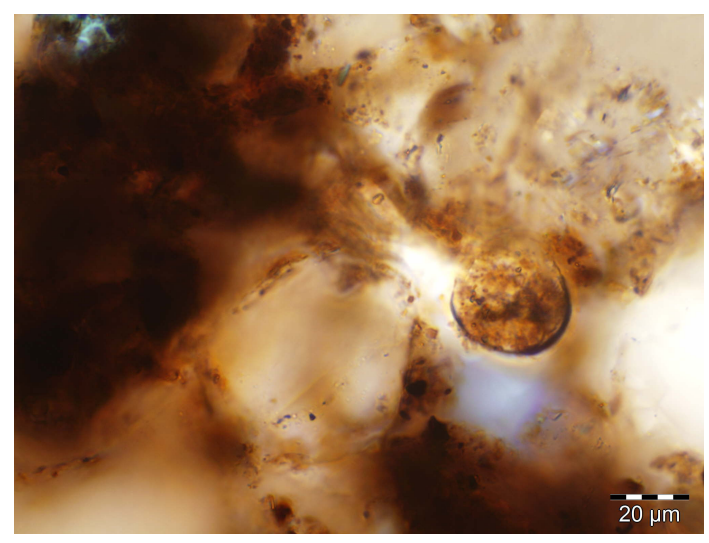

Figure 5. Pollen grains, visible in a welded aggregate of the same thin sections. Pollen grains in thin sections are observable as opaque, empty spheroidal objects. The palynological characteristics as sculpture and aperture are not visible without the chemical treatments during pollen extraction.

\subsection{Biomarker analysis}

\subsubsection{The application of the VERHIB model}

A detailed description of the biomarker approach using the VERHIB method is presented in our previous publications (Jansen et al., 2010, 2013; van Mourik and Jansen, 2013). Briefly, the basis of the method lies in the unraveling of the preserved concentration patterns of $\mathrm{C}_{20}-\mathrm{C}_{36}$ n-alkanes, which are exclusive to the epicuticular wax layers on leaves and roots of higher plants (Kolattukudy et al., 1976). While such an application in itself is not new (e.g. Pancost et al., 2002; Hughen et al., 2004) the novelty of our approach lies in the application of the VERHIB model that we specifically developed to unravel the mixed n-alkane signal encountered in soil or sedimentary archives (Jansen et al., 2010). The VERHIB model consists of a linear regression model that describes how a certain input of plant-derived compounds such as $n$-alkanes over time in a certain archive at a certain location, results in accumulation of these compounds. An inversion of the forward model is used to reconstruct the accumulation encountered with depth into its most likely vegetation origin (Jansen et al., 2010). An important aspect of biomarker analysis using VERHIB is that it is an indirect reconstruction. While the biomarker patterns, in the present study the n-alkanes, are directly measured, the reconstruction into the most likely combination of vegetation biomass input responsible for the observed pattern is inferred by the model. For this, several parameters must be inputted into the model (Jansen et al., 2010), the most important of which is the selection of the expected plant species that have been responsible for the input of biomass in the archive in question, and subsequent inclusion of their n-alkane signature in the VERHIB reference base. In the present study, the selection of species to include was based on the (expected) crop his- 
tory of the sites under study, as well as the anticipated origin of the stable fillings used as manure. An important matter of debate when using $n$-alkane patterns to reconstruct past vegetation input is the genotypic plasticity of the n-alkane patterns, in particular in relation to prevailing environmental factors such as climate (e.g. Shepherd and Griffiths, 2006). In a previous study focusing on vegetation of relevance for reconstructions in ecosystems in North-Western Europe where plaggic agriculture occurred, we found that while genotypic plasticity related to climatic factors may influence the signal, such influence does not eradicate the different vegetation origins (Kirkels et al., 2013). To limit external influences as much as possible, the vegetation selected for inclusion in the VERHIB reference base was sampled in close vicinity to the three study sites as much as possible. The first group of selected plant species concerned the main sources of stable fillings, used for the manure production: fermented litter from deciduous forest soils (Quercus robur, Betula pendula), grass sods from brook valleys (Molinia caerulea) and heath sods (Calluna vulgaris).

The second group concerned crop species. Close to the educational Field Study Centre Orvelte (Drenthe) is a traditional plaggic field where they continued with the cultivation of traditional crop species. There we sampled Fagopyrum esculentum, Spergula arvensis, Avena sativa, Secale cereal and Spergula arvensis. The modern crop species Zea mays corn was sampled on the Posteles.

The concentration patterns of the $n$-alkanes with carbon numbers 20-36 in the selected vegetation samples and in the soil samples were subsequently used as input for the VERHIB model (see Sect. 2.3.2 for a description of the extraction and analysis of the biomarkers).

A second parameter that must be considered in the application of VERHIB is input of leaf and root material. VERHIB considers the species-specific n-alkane patterns in plant roots separately from the patterns in plant leaves, and uses this to deal with the input of young root material at depth (Jansen et al., 2010). A first selection criterion here concerns whether or not leaf and root material can be expected to have entered the soil at all. For the deciduous forest soil material potentially used as stable fillings (Quercus robur, Betula pendula), exclusively leaf-derived biomass input is expected as the trees did not grow on-site. In contrast, for the crop species Zea Mays and Spergula Arvensis only root material is expected to have entered the soil in appreciable amounts as the leaf material is mostly removed during harvest. For the other species considered, both leaf and root material must be taken into account. A selection of root- and/or leaf-derived n-alkane patterns to be considered in the VERHIB reference base was made in accordance with the previous considerations. With respect to the ratio of input of leaf vs. root biomass as required by the model, no exact information is available for the soil profile under study. Therefore, for those species where both leaf and root material is considered to have possibly entered the soil, in line with the exploratory nature of the present study, we applied an assumed leaf/root biomass input ratio of 1.0 and assumed that while input of leaf material always occurred at the top of the soil profile, root input also occurred with depth. Since our pilot study in polycyclic driftsand deposits showed that VERHIB was unable to filter out root input sufficiently (van Mourik and Jansen, 2013), when interpreting the occurrence of a certain species with depth in the profiles under study as modeled by VERHIB, the possibility of young root input being responsible for the signal was explicitly taken into account.

Figure 6 shows a flow diagram that illustrates the functioning of the VERHIB modeling as well as the selection of parameters and reference base species as described above.

\subsubsection{Extraction and analysis of the biomarkers}

Approximately $0.1 \mathrm{~g}$ of each of the freeze-dried and ground vegetation and soil samples was extracted by accelerated solvent extraction (ASE) using a Dionex 200 ASE extractor. The extraction temperature was $75^{\circ} \mathrm{C}$ and the extraction pressure $17 \times 106 \mathrm{~Pa}$, employing a heating phase of $5 \mathrm{~min}$ and a static extraction time of $20 \mathrm{~min}$. Dichloromethane/methanol $(\mathrm{DCM} / \mathrm{MeOH})(93: 7 v / v)$ was used as the extractant (Jansen et al., 2006). The extracts were subsequently fractionated into three fractions containing the $n$-alkanes, the esters and the combination of alcohols and fatty acids respectively. For this, a silica column consisting of extracted cotton wool and silica gel was used, followed by elution with hexane, hexane / DCM $(4: 1)$ and DCM / Methanol $(9: 1)$ respectively. Separation of the n-alkanes took place by oncolumn injection of $1.0 \mu \mathrm{L}$ of the first fraction on a $30 \mathrm{~m}$ Rtx-5Sil MS column (Restek) with an internal diameter of $0.25 \mathrm{~mm}$ and film thickness of $0.1 \mu \mathrm{m}$, using $\mathrm{He}$ as a carrier gas. Temperature programming was $50^{\circ} \mathrm{C}$ (hold $2 \mathrm{~min}$ ); $40^{\circ} \mathrm{C} \mathrm{min}^{-1}$ to $80^{\circ} \mathrm{C}$ (hold $2 \mathrm{~min}$ ); $20^{\circ} \mathrm{Cmin}^{-1}$ to $130^{\circ} \mathrm{C}$; $4{ }^{\circ} \mathrm{C} \mathrm{min}^{-1}$ to $350^{\circ} \mathrm{C}$ (hold $10 \mathrm{~min}$ ). Subsequent MS detection in full scan mode used a mass-to-charge ratio $(\mathrm{m} / \mathrm{z})$ of 50-650 with a cycle time of $0.65 \mathrm{~s}$ and followed electron impact ionization $(70 \mathrm{eV})$. The $\mathrm{n}$-alkanes were identified from the total ion current (TIC) signal by their mass spectra (dominant fragment ion represented by $m / z=57$ ) and retention times and quantified using a deuterated internal standard $\left(\mathrm{d}_{42}-\mathrm{n}-\mathrm{C}_{20}\right.$ alkane (Jansen et al., 2010$)$ as well as a conventional external n-alkane standard.

Figure 7 presents the n-alkane biomarker distribution in the leaves and/or roots of the species, inserted in the reference base. The results show the odd-over-even chainlength predominance typical of higher plants (Kolattukudy et al., 1976). The observed variation in patterns and concentrations is in line with the variation found in other species in previous work (e.g. Jansen et al., 2006). 


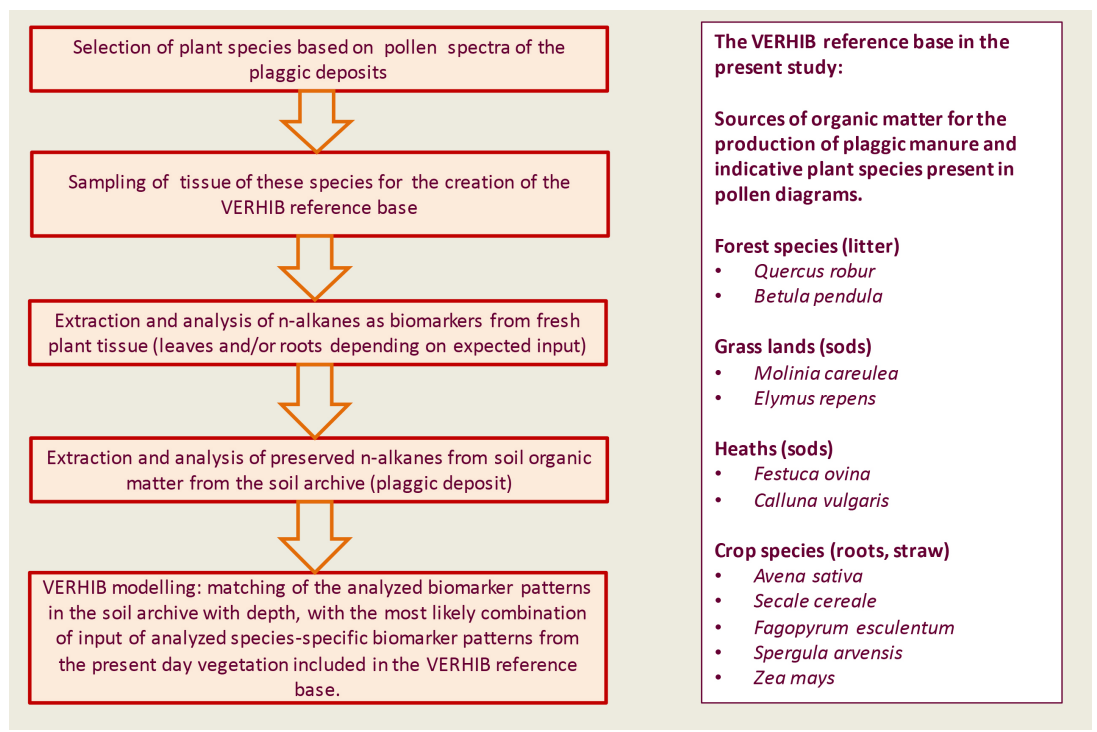

Figure 6. Flow diagram of the methodology of biomarker analysis.

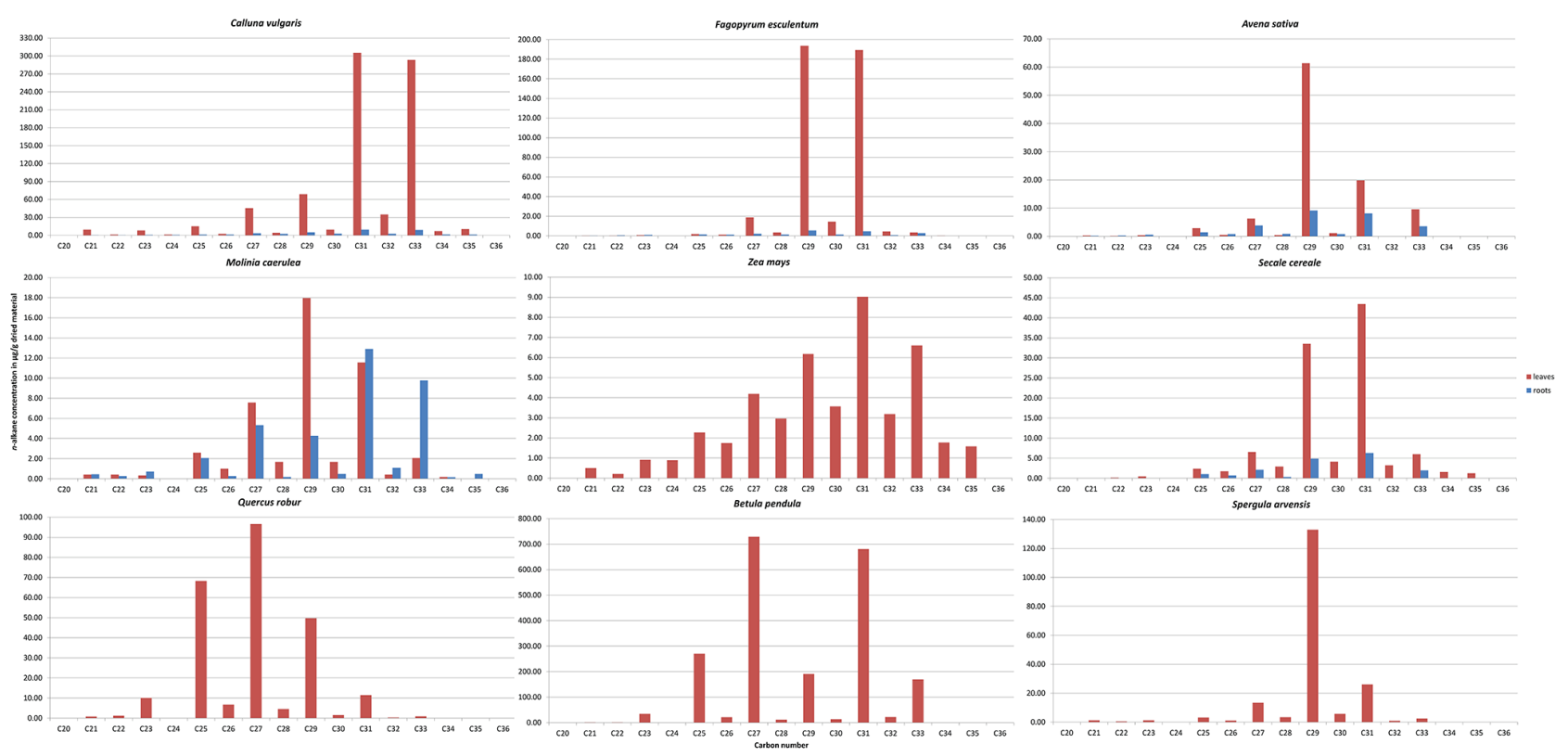

Figure 7. The n-alkane biomarker distribution in leaves and/or roots of species sampled, for the reference base of this pilot study.

\section{The vertical distribution of biomarkers and pollen in the analyzed profiles}

\subsection{Profile Valenakker}

Profile Valenakker is a plaggic Anthrosol (Aan), overlying a ploughed umbric Podzol (2ABp, 2Bs). The pollen diagram (Fig. 8) and the absolute dates (Table 1) reflect a soil development of $\approx 1400$ years.

The post sedimentary pollen spectra in the 2BS show percentages of tree species as Corylus and Quercus of the Middle sub-Atlantic. The presence of Poaceae, Cyperaceae,
Rumex and Ranunculaceae reflects a period of pasture. The high scores of Cerealia in ploughed $2 \mathrm{ABp}$ and even the $2 \mathrm{~B}$ indicate a form of sedentary agriculture before the start of plaggic agriculture. ${ }^{14} \mathrm{C}$ dating indicate a carbon age of the base $(60 \mathrm{~cm})$ of the Aan horizon of $\approx \mathrm{AD} 600$. The OSL age of the lower part of the plaggic horizon is $800-900$ years younger, $\approx \mathrm{AD} 1560$.

Micromorphological observations (Figs. 4, 5) of the plaggic deposits show the complexity of soil organic matter. There are various sources of organic carbon as plant roots, tissue of table fillings and sods. Also the composition of 


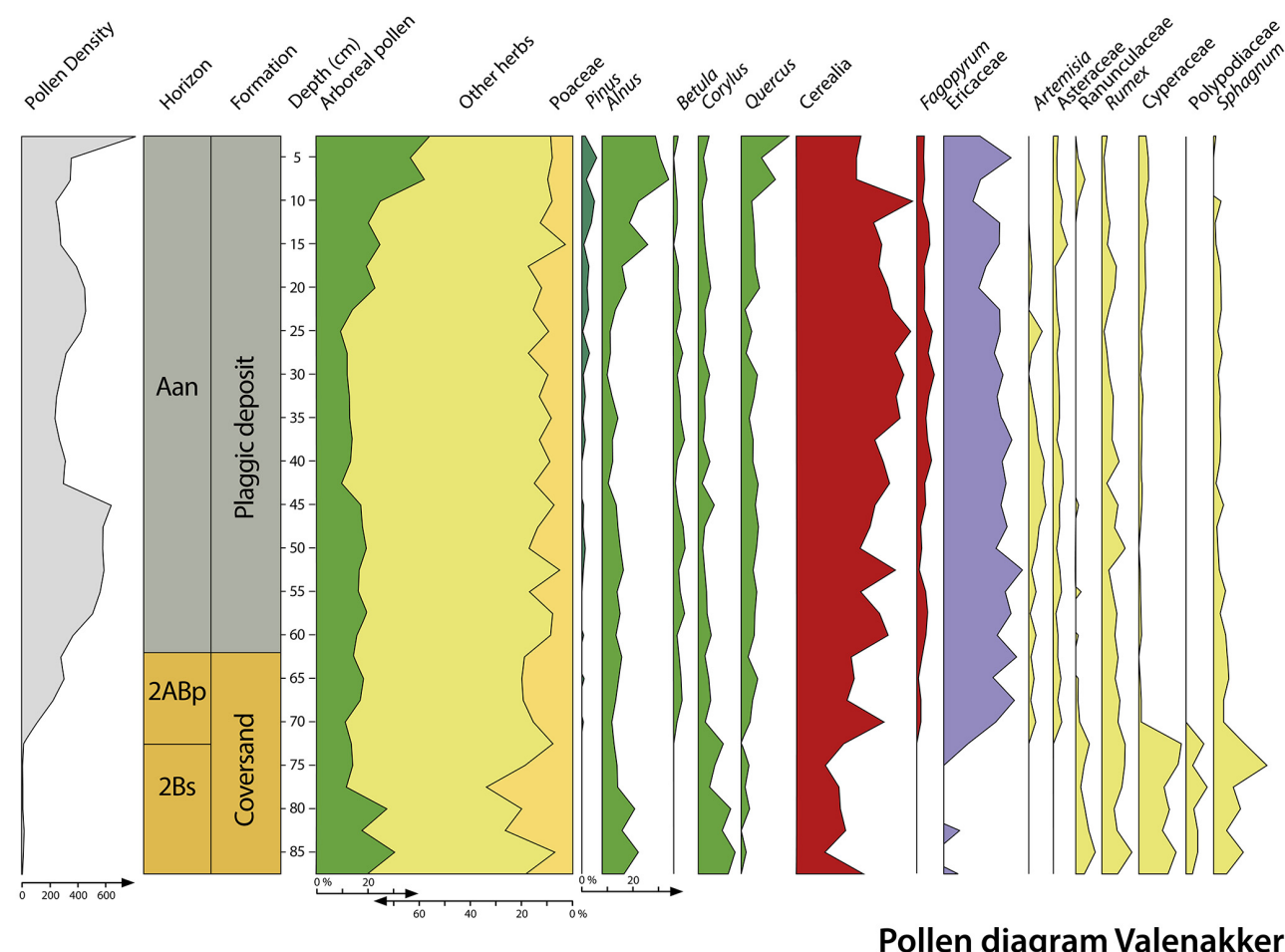

Figure 8. Pollen diagram Valenakker. Pollen density in $\mathrm{kgrain} \mathrm{mL}^{-1}$.

Table $1 .{ }^{14} \mathrm{C}$ and OSL dates of the plaggic deposits of Valenakker.

\begin{tabular}{lllll}
\hline Horizon & $\begin{array}{l}\text { Depth } \\
(\mathrm{cm})\end{array}$ & $\begin{array}{l}\text { Calendric } \\
{ }^{14} \mathrm{C} \text { ages } \\
\text { humin }\end{array}$ & $\begin{array}{l}\text { Calendric } \\
{ }^{14} \mathrm{C} \text { ages } \\
\text { humic acids }\end{array}$ & $\begin{array}{l}\text { Calendric } \\
\text { OSL ages }\end{array}$ \\
\hline Aan & 20 & - & - & AD 1775 \pm 20 \\
Aan & 40 & AD 771 \pm 92 & AD 1049 \pm 78 & AD 1635 \pm 30 \\
Aan & 60 & AD 595 \pm 61 & AD 698 \pm 54 & AD 1565 \pm 30 \\
\hline
\end{tabular}

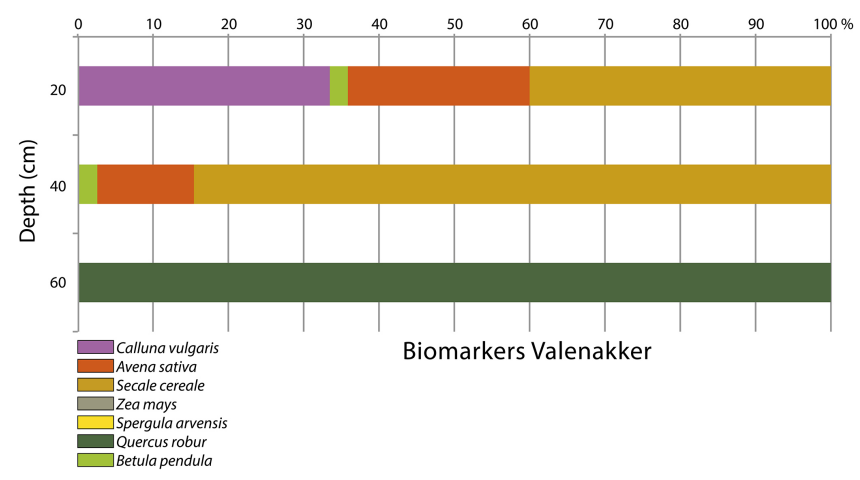

Figure 9. Biomarker diagram Valenakker.

pollen spectra is complex: it is a mix of the regular pollen influx of plants on the fields and in the surrounding areas infiltrating into the soil and pollen, and also the pollen present in various stable fillings.
In previous studies the origin of stable fillings, used in plaggic agriculture, was reconstructed on the basis of pollen diagrams (Spek, 2004; van Mourik et al., 2012a, b). The pollen spectra of the Aan horizon show very low scores of arboreal trees but reasonable scores of Ericaceae and Poaceae. Ericaceae pollen may indicate the use of heath sods, Poaceae pollen the use of grassland sods, the combination of sods from degrading heath and the rise of the land surface by plaggic manure is caused by the mineral fraction in such sods. However, the rise of the plaggic horizon of $\approx 60 \mathrm{~cm}$ cannot be explained by the use of heath sods if it is true that the use of heath sods (with a mineral fraction) was introduced in the course of the 18th century when better construction materials enabled the farmers to build deep stables (Vera, 2011). In fact, the sources of stable fillings cannot be satisfactorily detected with pollen diagrams. Additional information is provided by the biomarker diagram (Fig. 9).

The biomarker spectrum of the base is dominated by Quercus. Despite the low percentages Quercus pollen it is very likely that the farmers used forest litter as stable filling. The middle spectrum is dominated by markers of Avena and Secale. This points to the use of straw from these crop species as stable filling. Pollen of Cerealia is present in the whole diagram. In the upper spectrum biomarkers of Calluna are present together with Avena and Secale. This points to the use of heath sods as additional stable filling during the last phase in the development of the plaggic horizon. 


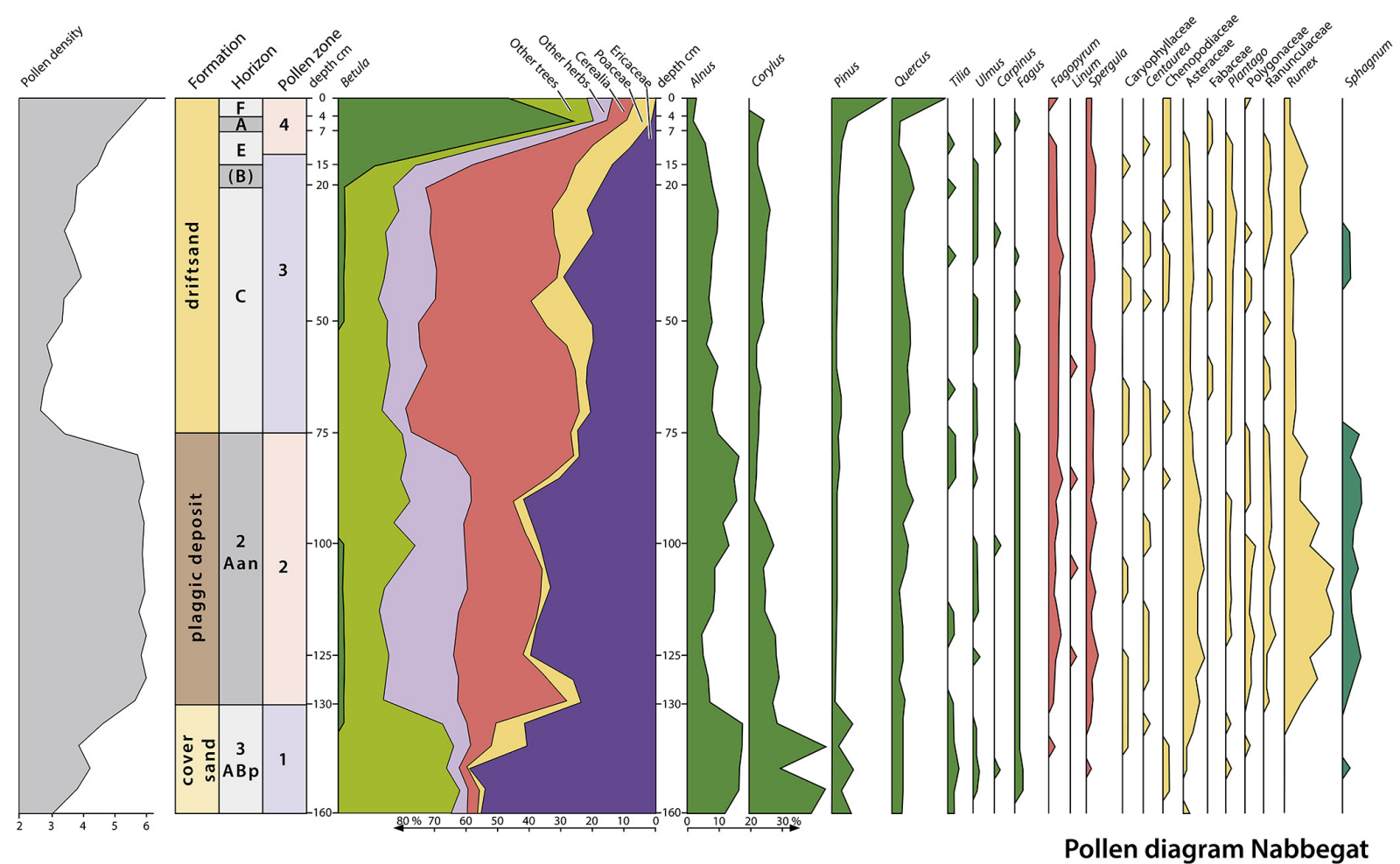

Figure 10. Pollen diagram Nabbegat. $\log D=$ pollen density in $\log \mathrm{kgrain}_{\mathrm{mL}} \mathrm{L}^{-1}$.

Table $2 .{ }^{14} \mathrm{C}$ and OSL dates of the plaggic deposits of Nabbegat.

\begin{tabular}{lllll}
\hline Horizon & $\begin{array}{l}\text { Depth } \\
(\mathrm{cm})\end{array}$ & $\begin{array}{l}\text { Calendric } \\
{ }^{14} \mathrm{C} \text { ages } \\
\text { humin }\end{array}$ & $\begin{array}{l}\text { Calendric } \\
{ }^{14} \mathrm{C} \text { ages } \\
\text { humic acids }\end{array}$ & $\begin{array}{l}\text { Calendric } \\
\text { OSL ages }\end{array}$ \\
\hline $\mathrm{C}$ & 70 & - & - & $\mathrm{AD} 1803 \pm 12$ \\
$2 \mathrm{An}$ & 80 & $\mathrm{AD} 428 \pm 107$ & $\mathrm{AD} 626 \pm 45$ & $\mathrm{AD} 1770 \pm 11$ \\
$2 \mathrm{An}$ & 105 & $37 \pm 133 \mathrm{BC}$ & $\mathrm{AD} \pm 101$ & - \\
$2 \mathrm{An}$ & 130 & $1182 \pm 139 \mathrm{BC}$ & $811 \pm 101 \mathrm{BC}$ & $\mathrm{AD} 1676 \pm 14$ \\
$3 \mathrm{ABp}$ & 140 & - & $1299 \pm 78 \mathrm{BC}$ & - \\
$3 \mathrm{ABp}$ & 150 & - & $1385 \pm 72 \mathrm{BC}$ & - \\
\hline
\end{tabular}

\subsection{Profile Nabbegat}

Profile Nabbegat is a haplic Arenosol (with Mormoder humus form), overlying a plaggic Anthrosol, overlying a ploughed umbric Podzol. The pollen diagram (Fig. 10) and the absolute dates (Table 2) reflect a soil development of $\approx 3000$ years.

The post sedimentary pollen spectra of the $3 \mathrm{ABp}$ reflect the start of agriculture (increase of Cerealia) on a former heath (decrease of Ericaceae) in a surrounding with coppice hedges (Quercus, Corylus). Based on radiocarbon dates, the agricultural activities started before $\approx 1000 \mathrm{BC}$, the OSL dates point to deposition of plaggic material after $\approx \mathrm{AD} 1500$.

The radiocarbon ages indicate that the farmers used organic matter with very little mineral "contamination" for a long time. The OSL ages indicate that the rise of the plaggic horizon started $\approx \mathrm{AD} 1500$ due to mineral grains as part of the manure. The plaggic horizon developed between AD 1500 and 1800. Around AD 1800, shortly after the introduction of the deep stable economy (Vera, 2011), the plaggic Anthrosol was overblown by driftsand. Apparently, the use of heath sods resulted in heath degradation, sand drifting and acceleration of the rise of the plaggic horizon (van Mourik et al., 2012a). The sand drifting stabilized under planted Quercus trees; the roots of these trees reached the buried Anthrosol and may have contributed to the scores of biomarkers in the upper part of the buried plaggic horizon. The composition of the pollen spectra of the plaggic horizon is rather uniform, dominated by Ericaceae and Cerealia.

Figure 11 shows the results of biomarker analysis. Biomarkers of Quercus were present in all the spectra, dominant in the lower spectra and regular in the other spectra. This points to the use of forest litter as stable filling during the development of the lower part of the plaggic horizon. The main crop species during this time was Spergula. The middle part is dominated by markers of Avena and Secale, indicating the use of straw. Only in the upper spectrum Calluna was found, indicating the use of heath sods during the last phase of the development of the plaggic horizon. 


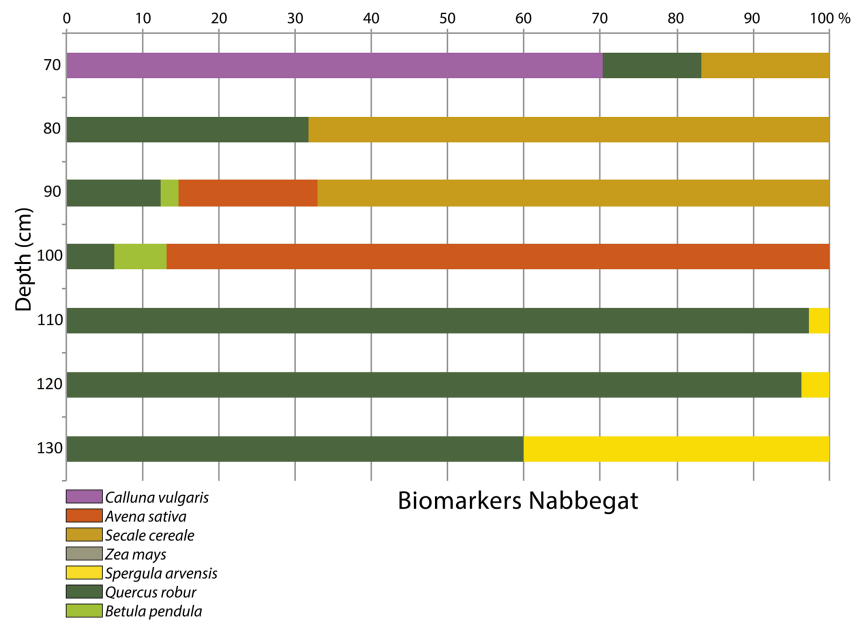

Figure 11. Biomarker diagram Nabbegat.

\subsection{Profile Posteles}

Profile Posteles is a plaggic Anthrosol, overlying a ploughed umbric Podzol. The pollen diagram (Fig. 12) and the absolute dates (Table 3) reflect a soil development of at least 1200 years.

The pollen content of the buried ploughed Podzol (2Ap, 2B) is post-sedimentary infiltrated in Late-Glacial cover sand by bioturbation and agriculture. Characteristic is the sharp decrease of pollen concentrations with depth, shown by the pollen density curve. The spectra of the $2 \mathrm{~B}$ horizon already reflect evidence of agriculture (Cerealia) in a deforested landscape (low percentages of Alnus, Quercus, Fagus). The spectra of the 2Ap horizon show increasing percentages of Cerealia.

The radiocarbon age of the base of the plaggic deposits $(95 \mathrm{~cm})$ is $\approx \mathrm{AD} 850$ and the OSL age $\approx \mathrm{AD} 1500$. The OSL age of the $2 \mathrm{Ap}(105 \mathrm{~cm})$ is $2035 \pm 450 \mathrm{BC}, \approx 3500$ years older than sample 95 . In this part of the profile we see the effect of bioturbation on the age of the cover sand. Grains from the base of the Aan were transported to the 2Ap and reversed, which explains the large standard deviation of the OSL of sample $105 \mathrm{~cm}$.

The actual Ap horizon (the active plough horizon) is palynologically characterized by peak percentages of Cerealia, a slight extension of Pinus (planted on the abandoned heath after AD 1900) and the appearance of Zea mays (introduced in Dutch agriculture after AD 1950). Pollen of Cerealia, Ericaceae and Poaceae were found in all the spectra of the Aan.

The lowest spectrum (80) is dominated by the crop species Spergula and the score of Quercus indicates the use of forest litter during the development of this part of the Aan. The biomarker diagram (Fig. 13) provides additional information.

The spectra 10, 20, 40, 60 are dominated by biomarkers from roots of Zea mays. This crop species was introduced around AD 1950, but the markers of the decomposed Zea
Table $3 .{ }^{14} \mathrm{C}$ and OSL dates of the plaggic deposits of Posteles.

\begin{tabular}{|c|c|c|c|c|}
\hline Horizon & $\begin{array}{l}\text { Depth } \\
\text { (cm) }\end{array}$ & $\begin{array}{l}\text { Calendric } \\
{ }^{14} \mathrm{C} \text { ages } \\
\text { humin }\end{array}$ & $\begin{array}{l}\text { Calendric } \\
{ }^{14} \mathrm{C} \text { ages } \\
\text { humic acids }\end{array}$ & $\begin{array}{l}\text { Calendric } \\
\text { OSL ages }\end{array}$ \\
\hline Aan & 45 & - & - & $\mathrm{AD} 1758 \pm 14$ \\
\hline Aan & 59 & - & - & $\mathrm{AD} 1711 \pm 20$ \\
\hline Aan & 70 & AD $1132 \pm 68$ & $\mathrm{AD} 1172 \pm 51$ & $\mathrm{AD} 1651 \pm 31$ \\
\hline Aan & 82 & - & - & $\mathrm{AD} 1626 \pm 20$ \\
\hline Aan & 95 & $\mathrm{AD} 884 \pm 82$ & AD $861 \pm 85$ & $\mathrm{AD} 1517 \pm 31$ \\
\hline $2 \mathrm{ABp}$ & 105 & - & - & $2035 \pm 450 \mathrm{BC}$ \\
\hline
\end{tabular}

roots seem to suppress all the others (this was not the case in the profiles Valenakker and Nabbegat). Spectrum 50 is dominated by Avena and Secale, spectrum 30 by Zea and Secale and spectrum 0 by Zea and Calluna. Again the use of heath sods seems restricted to the youngest part of the plaggic horizon.

\section{Discussion}

Pollen diagrams of plaggic Anthrosols provide valuable paleoecological information to reconstruct the soil dynamics during the plaggic agriculture. However, interpretation of pollen diagrams is complicated. Pollen grains, extracted from plaggic deposits, may originate from two sources (van Mourik et al., 2011). The first source concerns the regional pollen influx from flowering species and local flowering crop species. Pollen grains precipitate on the soil surface and may infiltrate into the Anthrosols by ploughing and bioturbation. This pollen influx will be mixed with the pollen content of materials, used as stable filling to produce manure.

Pollen will be preserved in plaggic deposits in the anaerobic and acid micro environment of humic aggregates, produced by worms and micro arthropods (van Mourik, 1999b, 2001). In general it is not possible to make a clear separation between pollen grains originating from the regular pollen influx or from materials as sods. Therefore, the identification of the various sources of stall fillings cannot be based on pollen analysis alone. Additional information, acquired by biomarker analysis proved very useful for this purpose.

In the pollen diagrams Fagopyrum is found in almost all the spectra of the plaggic deposits and in Valenakker and Nabbegat even in the top spectra of the buried ploughed Podzol, probably as a result of pollen infiltration. Fagopyrum as crop species on sandy soils was introduced after AD 1350 (Leenders, 1996). Based on this palynological time marker, plaggic deposition started around AD 1350.

The radiocarbon ages of plaggic deposits are much older. This is caused by (1) older organic carbon, present in the applied stable fillings (as forest litter) for the manure production and (2) accumulation of hardly decomposable organic carbon during active soil formation. Consequently, the radiocarbon dates overestimate the ages of the plaggic sediments, but approach the age of the introduction of agricultural soil 

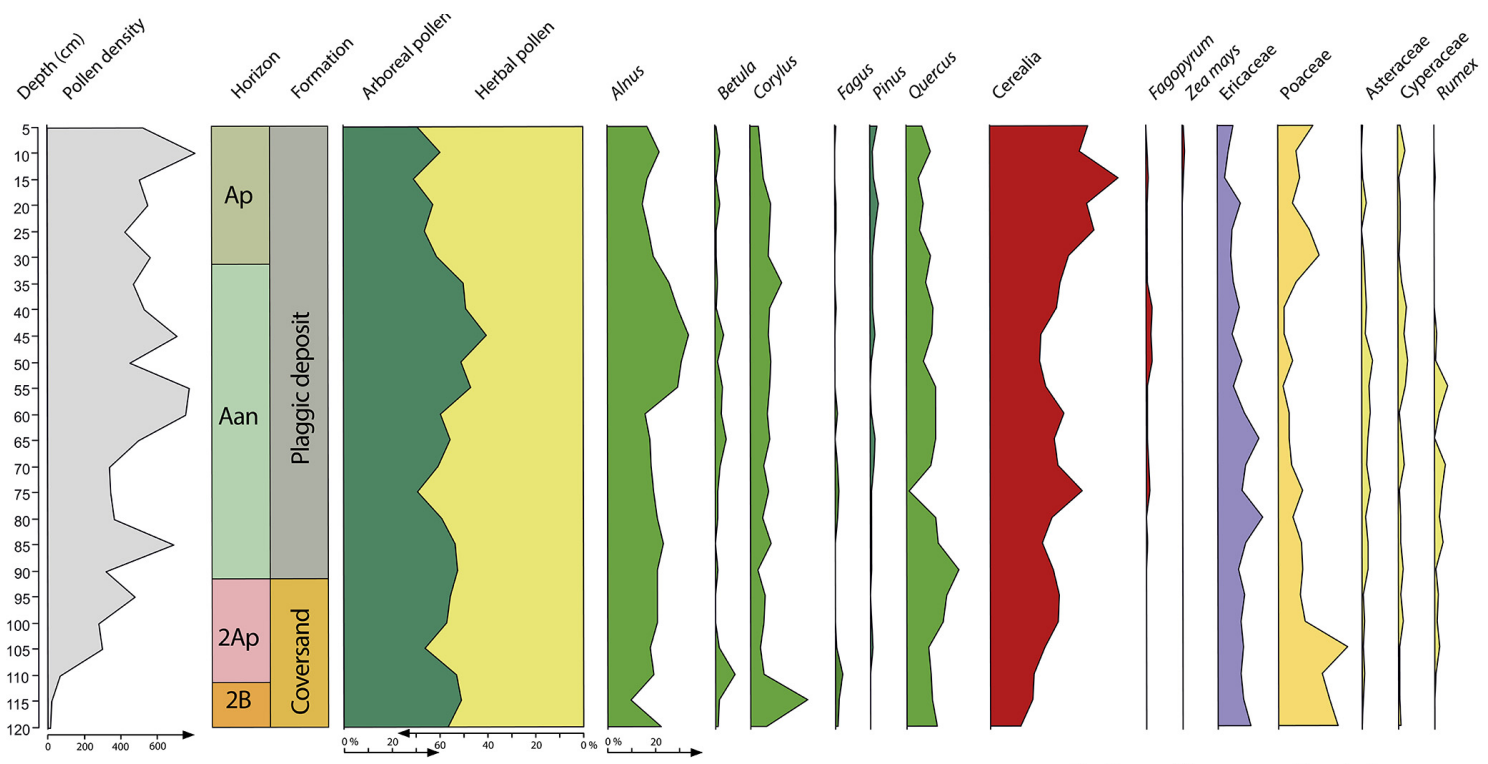

Pollen diagram Posteles

Figure 12. Pollen diagram Posteles; pollen density in $\mathrm{kgrain}_{\mathrm{mL}}{ }^{-1}$.

management (van Mourik et al., 1995, 2011, 2012a, b). Manuring of infertile soils already came in use in the Bronze Age and also the Celtic fields are an example of a prehistorical agricultural system based on manure management (Spek, 2004).

The mineral component of stable manure, applied on the fields, was responsible for the thickening of the plaggic horizon. Ploughing of the furrow will bleach the OSL signal of the mineral grains until the moment that the grains are no longer part of the active soil furrow. For that reason, OSL dating of the plaggic horizon provides reliable ages of the plaggic deposits (Bockhorst et al., 2005). The OSL dates of the profiles Valenakker, Nabbegat and Posteles indicate a start of the thickening $\approx \mathrm{AD} 1550$.

It was not possible to determine the sources of stable fillings palynologically. Possible stable fillings were forest litter, sods from moist grass lands and heat sods. But in almost all spectra of the pollen diagrams Ericaceae, Poaceae and arboreal pollen occur. Biomarkers extracted from plaggic deposits originate from two sources. The first source concerns biomarkers from decomposed roots of crop species, the second source of organic material as straw and sods, used as stable filling for manure production.

In the three diagrams we find Quercus as the dominant marker in the lowest part of the Aan horizon, indicating the use of forest litter. In Nabbegat, Quercus markers can also originate from roots of the planted Quercus forest after the stabilization of the sand drifting. This is not the case on Valenakker and Posteles. The middle part of the Aan horizon is dominated by markers of Avena and Secale, indicating the use of straw as stable filling.

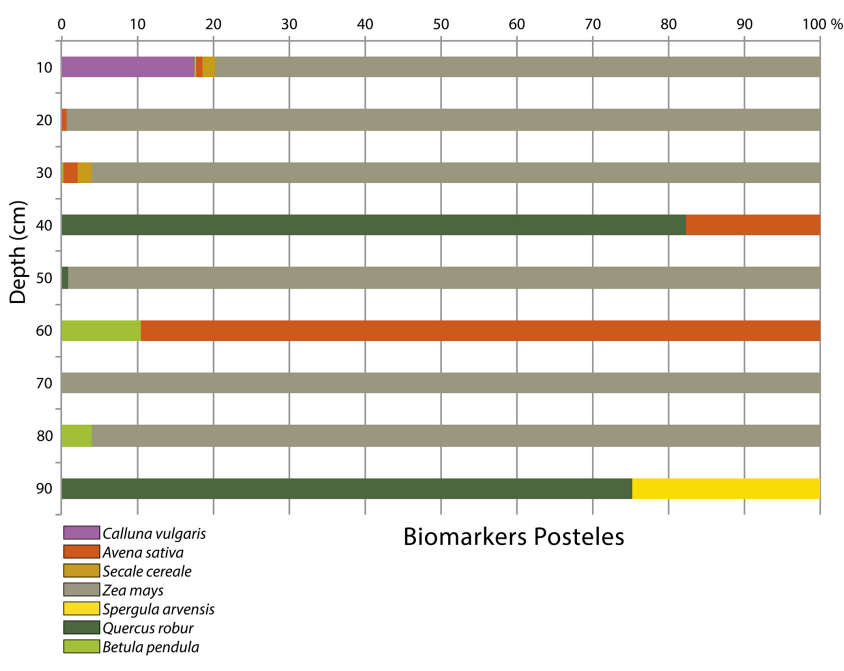

Figure 13. Biomarker diagram Posteles.

Only in the top of the Aan horizon markers of Calluna are present, indicating the use of heath sods as stable filling. Based on the results of the biomarker analysis we can conclude that heaths sods were used as stable filling only in the 18th and 19th century. This fits with the observations about the use of heaths in historical archives (Vera, 2011).

So the question rises about heath management before the introduction of the deep stable economy. Some researchers point to careful heath management before the 19th century. In interviews with farmers born before 1950, Burny (1999) collected essential information about historical heaths management in the Belgian Kempen. A historical study of land use in the Campina also indicated careful maintenance and 
sustainable use of valuable common fields (de Keyzer, 2014). Before the 19th century, heath sods were never dug on the dry Calluna heath, only on the moist Erica heath. These organic sods were not used as stable filling but as fuel for the furnace. Burning of Calluna heaths was the most important management action to rejuvenate the heath. Juvenile heath is food for cows. Sods digging was a bad action due to the resistance and incoherence of these dry sods and also the long recovery period. Mowing of older Calluna shrubs took place. Twigs were used for roofs, burning and brooms (Burny, 1999). Because of the very low nutrient contribution to the manure of mowed Calluna, the farmers preferred the use of twigs of broom (Genista). When in the course of the 18th century the authority relationships changed and the population growth and the demand for food increased, farmers started to intensify their production (Vera, 2011). They needed more manure and started with the deep stable economy and the use of $\mathrm{Cal}$ luna heath sods.

An important factor may be the presence of pollen and biomarkers in sheep droppings. According to Simpson et al. (1999) biomarkers survive the congestion process and stay in the manure. But what do sheep consume? Grazing sheep are very selective in collecting food (Oom et al., 2008; Smits and Noordijk, 2013). They prefer grasses (Molinia, Festuca and Corynephorous). Only in years when there is insufficient grass available at the end of the summer do they eat shoots of Calluna, which at that time was nourishing with high concentrations $\mathrm{Ca}, \mathrm{Mg}$ and $\mathrm{K}$ but no P. Only in pollen spectra from sheep droppings, collected during the summer season, Calluna pollen is present. During the flowering season of Calluna, the animals consume pollen, precipitated on the grasses. That explains the presence of Calluna pollen and the absence of Calluna biomarkers in the lower parts of the plaggic horizons.

If it is true that Calluna heath sods were dug only in the 18th and 19th century, how can we explain the mineral component in the plaggic manure, responsible for the rise of the land surface before that time?

According to Smits and Noordijk (2013) there are several sources of minerals. Firstly, a small amount of mineral grains will be incorporated in the manure during emptying out of the manure of the stable. Secondly, farmers had the knowledge that the addition of sand could improve the fertility of the soil. Not the leached and acid sand from heath sods but not leached sand, dug on sheep walks and in blown out depressions in nearby drift sand landscapes.

\section{Conclusions}

- The vertical zoning of biomarkers and pollen in plaggic horizons are different. Palynologically, the plaggic horizon is a homogenous, the biomarker diagrams show differentiation.
- We can identify various stable fillings used based on the vertical distribution of biomarkers.

- The biomarker spectra of the base layer of the plaggic horizon are dominated by biomarkers of deciduous trees litter (dominated by Quercus), indicating the use of organic matter from the forest floor.

- The biomarker spectra of the middle part of the plaggic deposits are dominated by crop species (Avena, Secale), indicating the use of straw from these species as stable filling during a relatively long time.

- Only the top spectra of the plaggic horizons are dominated by Calluna, indicating that heath sods were used as stable filling only during the last phase in the development of the plaggic horizon.

- Profile Posteles shows the impact of the contribution of biomarkers of roots of Zea mays, introduced around AD 1950, suppressing the other species.

- The negligible percentages of Calluna in biomarker spectra of plaggic deposits with the exception of the top, suggest an overestimating of the use of heath sods in the traditional interpretation of the genesis of plaggic horizons, the dominance of crop species in biomarker spectra of plaggic deposits suggests underestimating of the use of straw as source material for the production of organic stable manure to fertilize ancient arable fields.

Acknowledgements. We would like to thank Jap Smits (State Forestry) for his information about historical heath management and agriculture. We are grateful to Annemarie Philip (IBED, University of Amsterdam) for the preparation of the pollen slides, Hans van der Plicht (CIO, University Groningen) for production of the radiocarbon dates and Jakob Wallinga (NCL, Wageningen University) for the realization of the OSL dates. The digital illustrations were produced by Jan van Arkel (IBED, University of Amsterdam).

We thank Jakob Wallinga and an anonymous reviewer for their constructive remarks.

Edited by: S. Kluiving

\section{References}

Bastiaens, J. and van Mourik, J. M.: Bodemsporen van beddenbouw in het zuidelijk deel van het plaggenlandbouw areaal, Historisch Geografisch Tijdschrift, 1995, 81-90, 1995.

Beukenkamp, P. C. and Sevink, J.: Natuur en landschap, in: De Hoge Veluwe, natuur en kunst, Stichting nationaal park De Hoge Veluwe en Wanders Uitgeverij, Zwolle, 40-96, 2005.

Bokhorst, M. P., Duller, G. A. T., and van Mourik, J. M.: Optically Stimulated Luminescence Dating of a fimic anthrosol in the Southern Netherlands, J. Archaeol. Sci., 32, 547-553, 2005. 
Burny, J.: Bijdrage tot de historische ecologie van de Limburgse Kempen (1910-1950), Natuurhistorisch Genootschap in Limburg XLII(1), Maastricht, 1999.

de Keyzer, M.: The common denominator; the survival of the commons in the late medieval Campine area, University Antwerpen, Department of History, Belgium, 2014.

Doorenbosch, M.: Ancestral heaths; reconstructing the barrow landscape in the central and southern Netherlands, Sidestone Press, Leiden, 2013.

Hughen, K. A., Eglinton, T. I., Xu, L., and Makou, M.: Abrupt tropical vegetation response to rapid climate changes, Science, 304, 1955-1959, 2004.

ISRIC-FAO: World Reference Base for Soil Recourses 2006, World Soil Resources Reports 103, FAO, Rome, 2006.

Jansen, B., Nierop, K. G. J., Hageman, J. A., Cleef, A. M., and Verstraten, J. M.: The straight-chain lipid biomarker composition of plant species responsible for the dominant biomass production along two altitudinal transects in the Ecuadorian Andes, Org. Geochem., 37, 1514-1536, 2006.

Jansen, B., Van Loon, E. E., Hooghiemstra, H., and Verstraten, J. M.: Improved reconstruction of palaeo-environments through unravelling of preserved vegetation biomarker patterns, Palaeogeogr. Palaeocl., 285, 119-130, 2010.

Jansen, B., de Boer, E. J., Cleef, A. M., Hooghiemstra, H., MoscolOlivera, M., Tonneijck, F. H., and Verstraten, J. M.: Reconstruction of Late Holocene forest dynamics in northern Ecuador from biomarkers and pollen in soil cores, Palaeogeogr. Palaeocl., 386, 606-619, 2013.

Kirkels, F. M. S. A., Jansen, B., and Kalbitz, K.: Consistency of plant-specific n-alkane patterns in plaggen ecosystems: A review, The Holocene, 23, 1355-1368, 2013.

Kolattukudy, P. E., Croteau, R., and Buckner, J. S.: Biochemistry of plant waxes, in: Chemistry and biochemistry of natural waxes, edited by: Kolattukudy, P. E., Elsevier, Amsterdam, 1976.

Leenders, K. A. H. W.: De boekweitcultuur in historisch perspectief, Geografisch Tijdschrift, 21, 213-227, 1996.

Mook, W. G. and Streurman, H. J.: Physical and chemical aspects of radiocarbon dating, First Symposium on 14C and Archaeology, Groningen, PACT, 8, 31-55, 1983.

Moore, P. D., Webb, J. A., and Collinson, M. E.: Pollen analyses, Blackwell Scientific Publications, Oxford, 1991.

Oom, S. P., Sibbald, A. M., Hester, A. J., Miller, D. R., and Legg, C. J.: Impacts of sheep grazing a complex vegetation mosaic: Relating behavior to vegetation change, Agr. Ecosyst. Environ., 124, 219-228, 2008.

Pancost, R. D., Baas, M., van Geel, B., and Damsté, J. S. S.: Biomarkers as proxies for plant inputs to peats: an example from a sub-boreal ombrotrophic bog, Org. Geochem., 33, 675-690, 2002.
Pape, J. C.: Oude bouwlandgronden in Nederland, Boor en Spade, 18, 85-115, 1972.

Shepherd, T. and Griffiths, D. W.: The effects of stress on plant cuticular waxes, New Phytol., 171, 469-499, 2006.

Simpson, I. A., van Bergen, P. F., Perret, V., Elhmmali, M. M., David, J., Roberts, D. J., and Richard, R. P.: Lipid biomarkers of manuring practice in relict anthropogenic soils, The Holocene, 9, 223-229, 1999.

Smits, J. and Noordijk, J.: Heidebeheer: Moderne Methoden in een Eeuwenoud Landschap, KNNV uitgeverij, 2013.

Spek, T.: Het Drentse esdorpenlandschap. Een historischgeografische studie, Matrijs, Utrecht, 2, part VI, 725-967, 2004.

van Mourik, J. M.: Het stuifzand van Heeswijk-Dinther, Geografisch Tijdschrift, XXI, 327-337, 1987.

van Mourik, J. M.: The use of micromorphology in soil pollen analysis, Catena, 35, 239-257, 1999a.

van Mourik, J. M.: Spuren von Plaggenlandbau im Gebiet der Schleswiger Landenge, Offa, 47, 169-176, 1999 b.

van Mourik, J. M.: Pollen and spores, preservation in ecological settings, in: Palaeobiology II, edited by: Briggs, E. G. and Crowther, P. R., Blackwell Science, 315-318, 2001.

van Mourik, J. M. and Horsten, F.: De paleogeografie van de Valenakker, Weerter Jaarboek, 10, 105-118, 1995.

van Mourik, J. M. and Jansen, B.: The added value of biomarker analysis in palaeopedology; reconstruction of the vegetation during stable periods in a polycyclic driftsand sequence in SENetherlands, Quatern. Int., 306, 14-23, 2013.

van Mourik, J. M., Wartenbergh, P. E., Mook, W. J., and Streurman, H. J.: Radiocarbon dating of palaeosols in eolian sands, Mededelingen Rijks Geologische Dienst, 52, 425-439, 1995.

van Mourik, J. M., Slotboom, R. T., and Wallinga, J.: Chronology of plaggic deposits; palynology, radiocarbon and optically stimulated luminescence dating of the Posteles (NE-Netherlands), Catena, 84, 54-60, 2011.

van Mourik, J. M., Seijmonsbergen, A. C., Slotboom, R. T., and Wallinga, J.: The impact of human land use on soils and landforms in cultural landscapes on aeolian sandy substrates (Maashorst, SE Netherlands), Quatern. Int., 265, 74-89, 2012a.

van Mourik, J. M., Seijmonsbergen, A. C., and Jansen, B.: Geochronology of Soils and Landforms in Cultural Landscapes on Aeolian Sandy Substrates, Based on Radiocarbon and Optically Stimulated Luminescence Dating (Weert, SE-Netherlands), InTech, Radiometric Dating, 75-114, 2012b.

Vera, H.: ... Dat men het goed van den ongeboornen niet mag verkoopen, Gemene gronden in de Meierij van Den Bosch tussen hertog en hertgang 1000-2000, Uitgeverij BOXpress, Oisterwijk, Netherlands, 2011 (with English summary). 